\title{
The Legalhood of Artificial Intelligence: AI Applications as Energy Services
}

\author{
Lambrini Seremeti $^{1,2}$, Ioannis Kougias ${ }^{2,}$ * \\ ${ }^{1}$ School of Education, Frederick University, Nicosia, Cyprus \\ Email: lamprini.seremeti@gmail.com \\ ${ }^{2}$ Laboratory, of Interdisciplinary Semantic Interconnected Symbiotic Education Environments, \\ Department of Electrical and Computer Engineering, University of Peloponnese, Greece \\ Email: kougias@uop.gr \\ *Corresponding Author: Ioannis Kougias, Email: kougias@uop.gr
}

How to cite this paper: Lambrini Seremeti, Ioannis Kougias (2021). The Legalhood of Artificial Intelligence: AI Applications as Energy Services. Journal of Artificial Intelligence and Systems, 3, 83-92. https://doi.org/10.33969/AIS.2021.31006

Received: May 23, 2021

Accepted: June 7, 2021

Published: June 11, 2021

Copyright (C) 2021 by author(s) and Institute of Electronics and Computer.

This work is licensed under the Creative Commons Attribution International

License (CC BY 4.0).

http://creativecommons.org/licenses/by/4.0/

(c) (i) Open Access

\begin{abstract}
The importance of data has increased in the last century and these days it is an essential resource for any human activity as well as a vital component for our society. The use of $\mathrm{AI}$ is a major improvement in handling these data, the amount of which is becoming enormous. In a regulatory perspective, AI applications have an impact on the social and economic structure and the rights and values on which it is based upon. This paper is a crucial step on the path of building a consensus on the legal hypostasis of AI. It is our belief that unforeseeable and ground-breaking AI applications can be regulatorily tackled with respect to energy law.
\end{abstract}

Keywords

Artificial intelligence, data, energy services, supplementary law interpretation

\section{Introduction}

Nowadays, our society is rapidly changing into a raw data-based one [14] and the basic resources are no longer capital or natural resources, but data sets. With huge amounts of data being the core resource, the capability of effectively managing heterogeneous data is becoming a crucial factor which involves information technology, and especially Artificial Intelligence (AI). It deals with the ability of a machine to perceive and respond to its environment independently and to perform 
tasks that would typically require human intelligence and decision-making processes, without though the direct human intervention [17].

AI technology is now ubiquitous, through the term AI systems. Regularities are produced by exploring data structures so that algorithms acquire a skill, which, in turn, is used to inject intelligence into an everyday interactive machine acting without human intervention. From voice-powered personal assistants to autonomouslypowered self-driving vehicles, they are seeping into human environment affecting the way they live, communicate, work and entertain themselves [19]. Thus, AI systems are active components within our society. However, society is a living system, inherently complex, whose stability is a necessary condition for its survival. The crucial point is to craft a way to embed AI entities in human society in such a way as to ensure the legal consistency of the up to now established human-centered law model [2].

An irreversible trend in any modern society is its movement from a stable to an unstable status or vice versa. At the same time, dramatic advances in technology continue to shape the conduct of these social movements [12]. Furthermore, this societal transition continues to be driven by many factors, including the desire to replace humans in the performance of many "dull” tasks as well as significant cost considerations, involving AI systems [1]. AI is actually an indeterminate concept covering a vast, heterogeneous and constantly evolving series of applications that are based on data processing. This data processing entails societal transition and, in this regard, AI is deemed as the mechanism that convert data (energy resource) to task performance (useful work).

In this paper, we try to shed light on the notion of the legalhood, i.e., the legal hypostasis of AI entities, by exploring recent related literature. The key contribution of this paper is a discussion of the legalhood of AI, on the basis of the notion of "energy", which semantically aligns with AI systems. This should guide future research towards the critical path of defining the legal hypostasis of AI applications within the next generation hybrid environment of ambient intelligence where natural and artificial entities must co-evolve synergistically, and accelerate progress in governing AI in order to benefit the society.

Section 2 of the paper constitutes an effort to explain the need for granting a legal hypostasis to AI entities. Section 3 touches on ways on which AI instrument is identified by law. Section 4 introduces an alternative legal analogy for AI, and Section 5 gives a brief conclusion.

\section{The Issue of AI Legalhood}

Plato, in his work "Laws", refers to some principles of primary importance regarding 
Lambrini Seremeti et al.

laws, among which is that the laws should not be changed often, with emphasis to the natural law, i.e., the law that is eternal, unchangeable and valid in all societies, at all time. In contrast, Thrasymachus - one of the figures in the discussion in Plato's "State" - argues that law is what is set by the state and regulates social relations, depending on the prevailing conditions. It is obvious, then, that natural law reflects the concept of justice, while statutory law depends on its practical application and effectiveness in regulating social coexistence in a specific space and time. Consequently, statutory law concerns all the rules of law which regulate, in a compulsory way, the behavior of the involved actors - natural and legal persons - with the aim of social coexistence. In this conceptual formulation of statutory law, we observe that the rules of law regulate the behavior of the actors who have already been legally characterized as either natural or legal persons. What happens though when a new entity is involved? Should it be legally subjected- by analogy - to one of these categories or should legal science create a new structure for its legal hypostasis and then impose a new set of rules of law to regulate the behavior of the new entity as well?

Today, developments in technology necessarily entail the statutory law, since social relations that are created through technology ought to be regulated, e.g., buying and selling mobile things through social networks, employment contract signed via email, committing financial crime with bitcoins, a self-driving vehicle injuring pedestrians, etc. In all these activities, in addition to natural and legal persons, new entities are involved, which are created with the help of Artificial Intelligence. The question is how these new entities will be part of the application of the respective rule of law.

More specifically, a rule of law consists of two parts: (a) the factual - the set of conditions and facts, with which the legislature links the occurrence of the legal effect - and (b) the legal consequence - the rights and the obligations that, as desired results by the legislator, are created, altered, abolished, provided that the elements that constitute the factual one, are met - [13]. The application of a rule of law requires the process of transition from the abstract force of the rule of law, to its concretization, through legal reasoning, i.e., it is assessed whether the event in question includes all the elements of the actual, applicable rule of law, thus occurs or not the legal consequence that is provided for in the applicable rule of law. For example, in the event that a vehicle injures a pedestrian, the civil and criminal courts must determine, inter alia, the responsibility of the driver of the vehicle, who is considered a natural person in accordance with the provisions in force. In the event that a self-driving motor vehicle injures a pedestrian, how will the non-existent driver be found to be at fault, what will be the applicable provisions? The self-driving motor vehicle is an 
application of artificial intelligence, in other words a new entity, for which it is necessary to find a legal hypostasis so that through legal reasoning it can be reduced to the elements of the actual applicable provision.

\section{Related Work - AI in Law}

Regulating AI requires primarily defining it [8]. Yet, there is no consensus about what is to be understood by AI, it is clear, however, the distinction between $\mathrm{AI}$ and traditional software development. The first difference is that the AI algorithm rules and software implementation may themselves be dynamic and changeable as the machine learns. The second difference is that the very large datasets processing is at the center of AI.

Increasingly rapid adoption of AI has brought challenges for law and policy makers [5]. Indeed, regulators around the world are desperately seeking options to define the legal hypostasis of particular types of AI in order to adapt the suitable regulatory framework applicable to any AI-based everyday activity [9]. The relentless pursuit of a new legal characterization of AI continues to yield analogies or legal arrangements to consider in applying the law to AI environments. Focusing on AI systems, law experts have granted them several legal statuses, based on their features.

In January 2017, the EU Parliament's Legal Affairs Committee published a report introducing the electronic personality (e-personhood) for AI agents and self-learning robots. But this characterization seems to contradict a number of the grounds stated in law related to legal rights of a human being [10]. Next, in the European Agenda, another alternative was emerged, that of legal person of AI agents. This characterization seems to be appropriate only in the case of human involvement with the robot at least at a supervisory level. In July 2020, the European Parliament Legal Affairs Committee published a report proposing the AI-based applications as products. This characterization is found to be in contradiction with the dynamic and unforeseeable nature of AI applications.

In the legal perspective, a common method to handle new phenomena, such as AI, is to use legal analogies in order to choose the appropriate liability regime that should apply on new emerging entities. Many alternative analogies, such as property [4], quasi-persons [21], and agents [15], have been suggested with regards to the place of $\mathrm{AI}$ in our legal system, by independent researches. Each of these suggestions presents different difficulties to the applicability of a specific liability regime on AI entities. There is one main difficulty in using these analogies in the AI context, the unpredictability of AI entities.

In this paper, an alternative approach is proposed, which takes account of the peculiarities and problems of the new AI instrument, so as to protect the civil society 
Lambrini Seremeti et al.

actors who carry out several AI-based activities, by simultaneously taking into account, on the one hand the resources availability, and on the other the fundamental principles of law.

\section{Artificially Intelligent Energy}

After the text edit has been completed, the paper is ready for the template. Duplicate the template file by using the Save As command, and use the naming convention prescribed by your journal for the name of your paper. In this newly created file, highlight all of the contents and import your prepared text file. You are now ready to style your paper.

Any human activity presupposes energy consumption, given that energy can be considered as the cause of any change. Energy is a relatively poorly defined concept that it can be fully perceived by effect, e.g., vehicle movement. It can take a number of different forms (solar, wind energy, etc.), depending on its source. All sources of energy share the same feature, their use enable humans to carry out specific work. In order to take advantage of the potential of energy resources, humans produce energy conversion mechanisms or engines. Energy can be neither appeared out of nowhere nor disappeared, but it only changes from one form to another. A fundamental principle of energy states that the total energy is conserved, that is, the universal energy remains stable. It solely changes forms, changing the world. However, energy which is not applied, neither has a value in a micro-, nor in a macro-level sense for the prosperity of society. Applying it nowadays, typically involves information technology and especially AI.

THE AI HLEG proposed an updated definition of AI: “Artificial Intelligence (AI) refers to systems designed by human that, given a complex goal, act in the physical or digital world by perceiving their environment, interpreting the collected structured or unstructured data, reasoning on the knowledge derived from this data and deciding the best action(s) to take (according to pre-defined parameters) to achieve a given goal. AI systems can also be designed to learn to adapt their behavior by analyzing how the environment is affected by their previous actions” [7]. By this definition, it is evident that data powers AI systems.

In this respect, we can consider AI applications as mechanisms that humans have created in order to convert raw data (primary energy) to AI services (useful work). AI applications, such as augmented reality, biometrics, object tracking, robotics, sentiment analysis, speech recognition, semantics, information extraction uses a complex combination of programming techniques of Data Science that are applied to deal with a large-scale heterogeneous data [3]. Accepting the challenge of considering AI services as energy services, there is a need to be based on the 
assumption that data has always existed, but of a different nature than today. On this ground, humans found out a way to use technological advances to convert data (energy resource) by implementing AI applications to AI services (useful work) in order to make their life better. Data can be also considered as a reusable source of energy, since the same set of data can be used by different AI applications at the same time. Indeed, facial recognition used to unlock a phone uses data from a user profile. The same data are applied to mass surveillance AI service. Moreover, given that data is in abundance, it is virtually inexhaustible, and its use is environment-friendly (cyberspace pollution is an issue outside of the scope of this paper). Thus, it may be deemed that data is a new form of renewable energy source. Indeed, AI applications use data and produce more data, that is, this form of energy comes from processes that are constantly replenished. A visual representation of the given consideration is given in Figure 1.

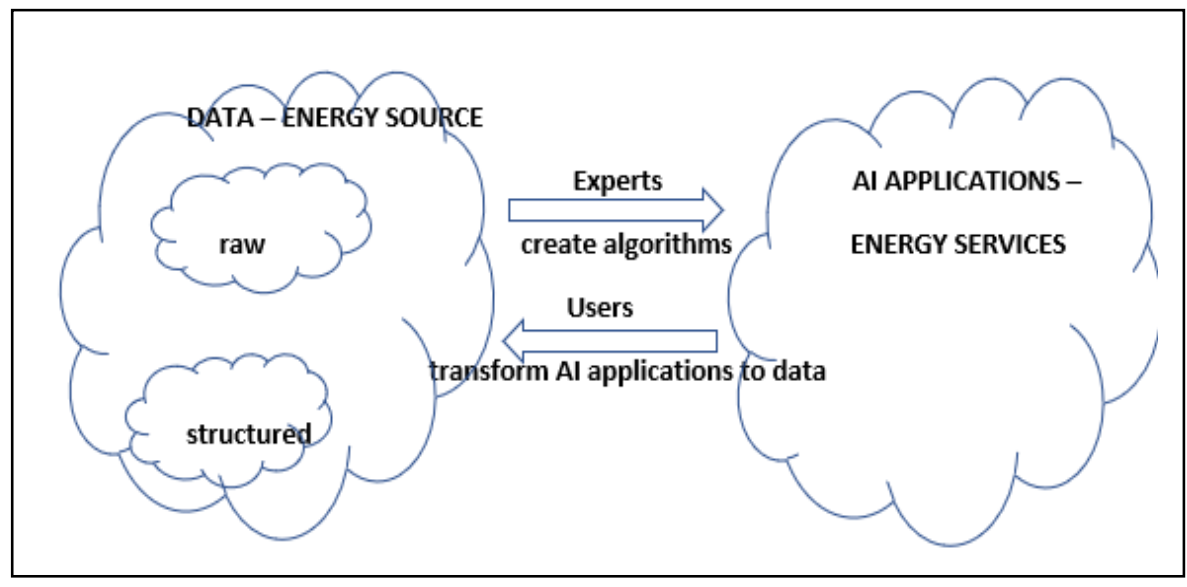

Figure 1. Visual representation of AI applications as energy services.

In the case of AI-based human activities, within, based on this consideration, AI applications convert data (energy resource) to AI services (beneficial work), any conflict of interest among their heterogeneous stakeholders can be resolved by involving Energy Law. It is a relatively new legal framework concerning all forms of energy services, from the division of energy resources, to production, transport, distribution and marketing. It also encompasses policies about environmental protection, as well as rules for conflict resolution at international level [16].

Law governs social life by providing conceptual structures for any action. Given that society is rapidly changing, there are created new types of complex relationships which need regulation. Seeing them through a legal lens, that is being able to choose the right legal terms to describe their stakeholders, is an important tool for justice. 
However, justice is not clearly defined in law, but rather is considered to be the outcome of legal case analysis. Meanwhile, it is constrained by inherent features of legal rules, such as, (a) ambiguity, which occurs where there is lack of clarity or when there is uncertainty about the application of a term, (b) lag between the time of establishment of a legal rule and its adoption time, and (c) under-inclusive anticipation, that is, a legal rule intends to apply to many people in a variety of situations, but it cannot encompass all possible situations. Due to these constraints in the grid of legal rules, law needs interpretation [20]. Therefore, in the case of AIbased activities, the supplementary interpretation of Energy Law may be applicable. The use of supplementary means of interpretation is important when the application of the general rule leaves the meaning ambiguous, obscure, or absurd (Article 32 of the Vienna Convention on the Law of Treaties of 1969). It is a special method of law interpretation, which is applied when there is a semantic gap in the legal grid, that is, when unregulated cases have arisen in the context of social change or when legislators have not anticipated specific cases. The appropriate solution to the problem of legal gap is either applying an analogous legal rule, or reasoning based on fundamental legal principles [18]. Such an unregulated case is that of the self-driving vehicle injuring a pedestrian. In this case, the possible responsible parties are the car owner, the driver using mobility service, the internet service provider, the infrastructure service provider, even the company provided that service.

Moreover, supplementary interpretation of rules of Energy Law can be applied to AIbased activities, since it is in line with a set of core principles [6], which also seem to be in line with the field of AI. For example, the principle of access to modern energy services, states that, "Ensure access to affordable, reliable, sustainable, and modern energy for all”. The key concept in Energy Law is 'energy services', since the key rationale behind this law is that energy in itself has no intrinsic value for society, but the lifestyle changes by the energy services provided. These energy services result from the combination of primary energy sources, technologies and infrastructure [11]. Thus, with the supplementary interpretation of Energy Law, data can be semantically aligned to energy resource, AI technologies to energy-related technologies, hardware to infrastructure, and AI applications to energy services.

In a nutshell, AI applications may be deemed energy services, since they detect patterns in data sets to consider certain outcomes, that is, specific task performance. Said otherwise, AI offers the appropriate mechanisms to convert raw data to useful work. On the one hand, data is deemed a newly defined energy source, and on the other hand, AI computational procedures process data in order to provide AI services. To this end, AI-based everyday activities involving human and artificial entities pose different regulation risks depending on the unforeseeable use of AI applications. The 
attempt to deliver a broad energy-based regulatory approach for the AI might be deemed to being both complete and effective. Complete, because it would be allinclusive of some technological developments that might occur and still be hard to frame, and effective, because to be sufficiently specific it may adequately focus on those peculiarities that give rise to relevant concerns and opportunities for society.

\section{Conclusion}

In this paper, a new path for the study and practice of AI regulation is set out. Indeed, in considering AI applications as the legal analogous of energy services, is in line with contemporary governmental policies around the world that have identified the importance of AI and put it high on the political agenda due to its social impact and economic consequences. This energy-based approach has emerged by the core set of principles of Energy Law. A set of principles looming ever larger in modern and complex societies, even as it faces challenges presented by new AI systems and new data processing-based methods. The approach presented here lays the ground for future work which will semantically align the core set of principles of the energy law to the AI field, in order to ensure social peace and prosperity among heterogeneous stakeholders, i.e., humans and AI entities, of the next generation AI environments. Moreover, a reference model based on Category Theory is investigated for understanding the interconnectedness and interdependencies among AI and Law.

\section{Conflicts of Interest}

The authors declare that there is no conflict of interest.

\section{References}

[1] Beard, J.M. (2018) The principle of proportionality in an era of high technology. In: W. S. Williams and C. M. Ford (eds) Complex Battlespaces: The Law of Armed Conflict and the Dynamics of Modern Warfare, Oxford University Press. http://dx.doi.org/10.2139/ssrn.3119384

[2] Bird, E., Fox-Skelly, J., Jenner, N., Larbey, R., Weitkamp, E., Winfield, A. (2020) The ethics of artificial intelligence: Issues and initiatives. Study of the Panel for the Future of Science and Technology for the European Parliament. DOI: $10.2861 / 6644$.

[3] Boire, R. (2018) Understanding AI in a world of bid data. Big Data and Information Analytics, Vol. 3, No. 1, 22-42. DOI: 10.3934/bdia.2018001.

[4] Brown, R.D. (2020) Property ownership and the legal personhood of artificial intelligence. Information \& Communications Technology Law, Vol. 30, Issue 2, 208-234. DOI: 10.1080/13600834.2020.1861714.

[5] Chesterman, S. (2020) Artificial intelligence and the limits of legal personality. International \& Comparative Law Quarterly, Vol. 69, No. 4, 819-844. DOI: $10.1017 /$ S0020589320000366. 
Lambrini Seremeti et al.

[6] Daci, J. (2010) Legal principles, legal values and legal norms: are they the same or different? Academicus International Scientific Journal, Vol. 2, 2010, ISSN: 2309-1088-2010-02-11.

[7] The European Commission's High-Level Expert Group on Artificial Intelligence. (2018) A definition of AI: Main capabilities and scientific disciplines. https://ec.europa.eu/newsroom/dae/document.cfm?doc_id=56341

[8] European Commission. (2020) Artificial Intelligence and Civil Liability. https://europarl.europa.eu/RegData/etudes/STUD/2020/621926/IPO L_STU(2020)621926_EN.pdf

[9] European Commission. (2021) New rules for Artificial Intelligence Q\&As. https://ec.europa.eu/commission/presscorner/detail/en/QANDA_21_16 $\underline{83 \# 1}$

[10] Gordon, J.S. (2020) Artificial moral and legal personhood. AI \& Soc. https://doi.org/10.1007/s00146-020-01063-2

[11] Heffron, R.J., Ronne, A., Tomain, J.P., Bradbrook, A., K. Talus, K. (2018) A treatise for energy law. The Journal of World Energy Law \& Business, Vol. 11, Issue 1, 34-48. https://doi.org/10.1093/jwelb/jwx039

[12] Imhonopi, D., Onifade, C.A., Urim, U.M. (2013) Collective behaviour and social movements: a conceptual review. Research on Humanities and Social Sciences, Vol. 3, No. 9, 76-85. Online ISSN: 2222-2863, www.iiste.org

[13] Kastellec, J.P. (2007) The structure of legal rules and the analysis of judicial decisions. Available at SSRN: http://dx.doi.org/10.2139/ssrn.960190

[14] Lee, A.J., Cook, P.S. (2020) The myth of the "data-driven" society: Exploring the interactions of data interfaces, circulations, and abstractions. Sociology Compass, Vol. 14, Issue 1. https://doi.org/10.1111/soc4.12749

[15] Lior, A. (2020) AI entities as AI agents: artificial intelligence liability and the respondeat superior analogy. Mitchell Hamline Law Review, Vol. 46, Issue 5. https://open.mitchelhamline.edu/mhlr/vol46/iss5/2

[16] Nordtveit, E. (2020) International energy law in perspective. The relationship between national and international energy law. Routledge Handbook of Energy Law. https://www.routledgehanbooks.com/doi/10.4324/9780429450891-4

[17] Ponnusamy, B. (2018) The role of artificial intelligence in future technology. International Journal of Innovative Research in Advanced Engineering, Vol. 5, Issue 4, 146-148. DOI: 10.26562/IJIRAE.2018.APAE10087

[18] Sbolci, L. (2011) Supplementary means of interpretation. In: E. Cannizzaro, The Law of Treaties Beyond the Vienna Convention, Oxford Scholarship Online. DOI: 1093/acprof:oso/9780199588916.001.0001

[19] Stone, P., Brooks, R., Brynjolfsson, E., Calo, R., Etzioni, O., Hager, G., Hirschherg, J., Kalyanakrishnan, S., Kamar, E., Kraus, S., Leyton-Brown, K., Parkes, D., Press, W., Saxenian, A., Shah, J., Tambe, M., Teller, A. (2016) Artificial Intelligence and Life in 2030. One Hundred Year Study of Artificial Intelligence: Report of the 2015-2016 Study Panel, Stanford University, Stanford, CA. 1-52. DOI: ai100.stanford.edu/2016-report

[20] Zariski, A. (2014) Legal interpretation. Skills and techniques for making sense of Law. In: A Zariski, Legal Literacy: An Introduction to Legal Studies, AU Press. DOI: 10.15215/aupress/9781927356449.01 
Lambrini Seremeti et al.

[21] Zibren, J. (2018) Legal personhood: animals, artificial intelligence and the unborn. Marasyk University Journal of Law and Technology, Vol. 12, Issue 1, 81-87. DOI: 10.5817/MUJLT2018-1-5 